\title{
Sustained endogenous glucose production, diminished lipolysis and non-esterified fatty acid appearance and oxidation in non-obese women at high risk of type 2 diabetes
}

Shareen Forbes, Stephen Robinson, Jason Dungu, Victor Anyaoku, Peter Bannister, David Forster ${ }^{1}$, Sujata Dissanayake ${ }^{1}$, Mark I McCarthy ${ }^{2}$, Ian A MacDonald ${ }^{1}$, Soundararajan Venkatesan and Desmond G Johnston Section of Endocrinology and Metabolic Medicine, Faculty of Medicine, Imperial College London, St Mary's Hospital, 2nd Floor, Mint Wing, Praed Street, London W2 1NY, UK, ${ }^{1}$ School of Biomedical Sciences, University of Nottingham Medical School, Nottingham, UK and ${ }^{2}$ Oxford Centre for Diabetes, Endocrinology and Metabolism, Churchill Hospital, Oxford, UK

(Correspondence should be addressed to S Forbes; Email: shareen.forbes@imperial.ac.uk)

\begin{abstract}
Objective: To evaluate early defects in glucose production, lipolysis and fatty acid oxidation in nonobese, normally glucose tolerant women, who are nevertheless at risk of type 2 diabetes.

Methods: Ten women with previous gestational diabetes (pGDM) and ten controls were studied in two $4 \mathrm{~h}$ infusions of stable isotopes $6,6-{ }^{2} \mathrm{H}_{2}$-glucose, $1-{ }^{13} \mathrm{C}$-palmitate, and $1,1,2,3,3-{ }^{2} \mathrm{H}_{5}$-glycerol with and without infusion of adrenaline. Fatty acid oxidation was quantified using indirect calorimetry and ${ }^{13} \mathrm{CO}_{2}$ measurements. Insulin sensitivity was evaluated using the short insulin tolerance test. Results: The pGDM and control women were non-obese and carefully matched for body mass index and fat mass. Whole body insulin sensitivity and basal insulin concentrations did not differ significantly but basal glucose concentrations were increased in women with pGDM. During a $0.9 \%$ saline infusion, glucose appearance was not significantly different at the first (90-120 min) and second (210-240 min) steady states. However, glucose appearance decreased in controls but was maintained in the pGDM women $(-0.33 \pm 0.02$ vs $-0.03 \pm 0.08 \mathrm{mg} / \mathrm{kg}$ per $\mathrm{min} ; P=0.004)$. Basal glycerol appearance $(0.27 \pm 0.02$ vs $0.38 \pm 0.03 \mathrm{mg} / \mathrm{kg}$ per $\mathrm{min} ; P=0.02)$, palmitate appearance $(0.74 \pm 0.09$ vs $1.05 \pm 0.09 \mathrm{mg} / \mathrm{kg}$ per $\mathrm{min} ; P=0.03)$ and palmitate oxidation $(0.07 \pm 0.01 \mathrm{vs} 0.10 \pm 0.01 \mathrm{mg} / \mathrm{kg}$ per min; $P=0.03$ ) were lower in the pGDM women. During the adrenaline infusion, changes in glucose, glycerol and palmitate concentrations and kinetics were similar in both groups.

Conclusions: Sustained glucose production during fasting is an early abnormality in non-obese subjects at risk of type 2 diabetes. Lipolysis and non-esterified fatty acid appearance and oxidation are diminished, suggesting an increased tendency to store fat. The observations are not readily attributable to differences in insulin or catecholamine sensitivity.
\end{abstract}

European Journal of Endocrinology 155 469-476

\section{Introduction}

Type 2 diabetes is characterised by increased circulating glucose concentrations: impaired insulin secretion and action, characteristic of the diabetic state, lead to decreased glucose utilisation by muscle and enhanced hepatic glucose production. Diminished suppression by insulin of lipolysis, non-esterified fatty acid (NEFA) appearance and very low-density lipoprotein production by the liver lead to elevated circulating glycerol, NEFA and triglyceride (TG) concentrations. Little is known about the emergence of these metabolic defects prior to the development of frank diabetes. Gestational diabetes (GDM) is carbohydrate intolerance, first diagnosed during pregnancy. Women with previous GDM (pGDM) and normal glucose tolerance (NGT) post-partum, are at risk of developing type 2 diabetes, especially if overweight $(1,2)$, and serve as a model of the pre-diabetic state. Following a $75 \mathrm{~g}$ oral glucose tolerance test (OGTT), glycerol and 3-hydroxybutyrate concentrations may be elevated compared to age, race and body mass index (BMI)matched controls, compatible with impaired suppression of lipolysis (3). This may be secondary to a relative deficiency of insulin after a meal (3). Diminished suppression of NEFA to insulin, reflecting insulin resistance is also seen (4). Most studies have, however, been confounded by subjects being overweight or obese $(3,4)$. It is therefore difficult to assess changes due to the pre-diabetic state separate from the obese state. Although concentration differences have been described, they provide no information about turnover (3). No study has examined glucose, glycerol and palmitate kinetics with stable isotopes simultaneously in a prediabetic group with NGT. In the present study, we aimed to compare glucose, glycerol and palmitate metabolism 
both basally and following catecholamine stimulation, in a group of non-obese women with pGDM carefully matched with controls for weight and fat mass (FM).

\section{Subjects, materials and methods}

\section{Subjects}

Over a 2-year period, ten European women with pGDM (diagnosed in index pregnancy with $75 \mathrm{~g}$ OGTT at 24-28 weeks gestation by World Health Organisation (WHO) criteria) and ten controls were recruited retrospectively (via antenatal care database) at St Mary's Hospital, London: index GDM pregnancy fasting plasma glucose (mean \pm s.E.M.), $121 \pm 5$ and 2 -h glucose, $148 \pm$ $2 \mathrm{mg} / \mathrm{dl}$. No pGDM woman had required insulin treatment during the index pregnancy. Control subjects had a normal glucose challenge test during pregnancy (plasma venous glucose $<140 \mathrm{mg} / \mathrm{dl}(122 \pm 4 \mathrm{mg} / \mathrm{dl})$ after $50 \mathrm{~g}$ oral glucose). During the index pregnancy there was no difference in age, $36 \pm 2$ vs $36 \pm 2$ years, BMI at term $\left(27.0 \pm 0.8\right.$ vs $\left.26.6 \pm 0.7 \mathrm{~kg} / \mathrm{m}^{2}\right)$, parity ( $3 \pm 0$ vs $2 \pm 0$ ), or time since delivery $(6 \pm 1$ and $4 \pm 1$ years) in the pGDM vs control women respectively. There was a family history of type 2 diabetes in two of the subjects with pGDM but no family history of GDM or known monogenic forms of diabetes in either group. At recall, all women had a $75 \mathrm{~g}$ OGTT and NGT according to WHO criteria: fasting glucose $(95 \pm 4$ vs $86 \pm 2 \mathrm{mg} / \mathrm{dl} ; P=0.04$ ) and 2 -h glucose $108 \pm 7$ vs $79 \pm 4 \mathrm{mg} / \mathrm{dl} ; P=0.01)$ in $\mathrm{pGDM}$ and control women respectively (5). The women were selected to be nonobese and of Northern European descent and carefully matched for BMI and FM. No women were pregnant or breast feeding and all had normal renal and thyroid functions. Subjects were studied in the follicular phase of the menstrual cycle except for two women, one from each group, who were taking the combined oral contraceptive pill and were studied on days $3-5$ in their 'pill-free' week. Body weight was determined on an electronic scale. FM and fat-free mass (FFM) were measured by near-infrared light spectroscopy. Waist and hip circumference measurements were made with the subjects standing in the upright position to the nearest $0.5 \mathrm{~cm}$, halfway between the spina iliaca and the last rib, and at the trochanter major respectively. Subjects provided written informed consent before participation in these studies, which were approved by an institutional review board (St Mary's Hospital Ethics Committee), and conducted in accordance with the principles endorsed by the Declaration of Helsinki.

\section{Assessment of insulin sensitivity}

This was assessed by the short insulin tolerance test (SITT) (6). Subjects were studied in the metabolic day unit after an overnight fast of 10-12 h and asked to observe their usual diet and abstain from alcohol or strenuous exercise for the previous 3 days. A 44-mm, 20 gauge cannula was placed retrogradely into a vein in the forearm and heated to $40-50^{\circ} \mathrm{C}$ in a warm air box to arterialise the superficial venous blood for sampling. A second 44-mm, 20 gauge cannula was placed in the antecubital vein of the contralateral arm to allow administration of short-acting insulin $(0.05 \mathrm{U} / \mathrm{kg}$ body weight) at time $0 \mathrm{~min}$, and samples taken at $-15,0,3$, $4,6,7,8,9,10,11,12,13,14$ and 15 min for plasma glucose and NEFA estimation. The test was stopped at $15 \mathrm{~min}$. A carbonated glucose drink (Lucozade Original; GlaxoSmithKline) and complex carbohydrate, such as a sandwich, was given immediately following the study to avoid hypoglycaemia. Samples were centrifuged for $15 \mathrm{~min}$ at $4^{\circ} \mathrm{C}$ at $2000 \mathrm{~g}$, plasma separated, stored at $-70{ }^{\circ} \mathrm{C}$, and later analysed for glucose and NEFA concentrations. The linear slope of the glucose decline from 3 to $15 \mathrm{~min}$ after the insulin, was the measure of insulin sensitivity expressed as milligrams per litre per minute (mg/l per min). The NEFA measurements provided an assessment of the effect of insulin on lipid metabolism. Homeostasis model assessment (HOMA) was performed on the post-absorptive glucose and insulin concentrations to provide an independent analysis of insulin action $(7,8)$.

\section{Infusion studies with adrenaline and normal saline}

Infusion studies took place on separate study days in the metabolic day unit after an overnight fast of 10-12 h. All studies were completed within 12 weeks. Subjects were allowed to drink water ad libitum during this time. They had abstained from alcohol and physical exercise and consumed a diet containing at least $150 \mathrm{~g}$ carbohydrate for at least 3 days prior to the test. For blood sampling, a 44-mm, 20 gauge cannula was inserted retrogradely into the superficial vein in the dorsum of the hand and kept patent with an infusion of $0.9 \%$ (normal) saline. This hand rested in a warm air box $\left(40-50{ }^{\circ} \mathrm{C}\right)$ to obtain arterialised venous blood samples. Blood samples were withdrawn via a threeway tap with the first $2 \mathrm{ml}$ discarded to avoid contamination with saline. A second cannula was placed in an ipsilateral antecubital vein for the infusions of the stable isotopes and adrenaline or saline.

The stable non-radioactive isotopes $6,6-{ }^{2} \mathrm{H}_{2}$-glucose, $1-{ }^{13} \mathrm{C}$-palmitate and $1,1,2,3,3-{ }^{2} \mathrm{H}_{5}$-glycerol, were used to measure the rate of glucose appearance, NEFA appearance and oxidation, and whole body lipolysis respectively.

Blood samples were taken at time 0 , for measurement of background enrichment (natural abundance levels) of plasma $6,6-{ }^{2} \mathrm{H}_{2}$-glucose, $1-{ }^{13} \mathrm{C}$-palmitate, and $1,1,2,3,3-{ }^{2} \mathrm{H}_{5}$-glycerol and two samples of expired air were collected via a Douglas bag into evacuated glass 
tubes for measurement of background ${ }^{13} \mathrm{CO}_{2}$ enrichment.

A priming dose of $\mathrm{NaH}^{13} \mathrm{CO}_{3}$ (99\% APE, Cambridge Isotopes, MA, USA) $110.5 \mu \mathrm{g} / \mathrm{kg}$ was given, followed by a primed dose $(4.6 \mathrm{mg} / \mathrm{kg})$ continuous infusion (4.0 mg/kg per h) of $6,6-{ }^{2} \mathrm{H}_{2}$-glucose, a primed dose $(0.05 \mathrm{mg} / \mathrm{kg})$ continuous infusion $(0.29 \mathrm{mg} / \mathrm{kg}$ per $\mathrm{h})$ of $1,1,2,3,3-{ }^{2} \mathrm{H}_{5}$-glycerol and a continuous infusion of $1-{ }^{13} \mathrm{C}$-palmitate $(10.3 \mu \mathrm{g} / \mathrm{kg}$ per $\mathrm{min})$. After $2 \mathrm{~h}$ of study, an i.v. infusion of adrenaline $(25 \mathrm{ng} / \mathrm{kg}$ per $\mathrm{min})$ was established and all infusions continued for a further $2 \mathrm{~h}$. This dose of adrenaline achieves 4-10 times basal plasma levels and avoids vasoconstriction (9). On a separate occasion, an infusion of $0.9 \%$ saline was used in place of adrenaline. The subject was blinded to the infusion received and the order of the infusion randomised. Four arterialised blood samples were taken for enriched and unenriched glucose, glycerol and palmitate, adrenaline and noradrenaline, insulin, NEFA, 3-hydroxybutyrate and lactate at 10 min intervals between time 90 and 120 min (termed first steady state (1SS)) and between 210 and $240 \mathrm{~min}$ (termed second steady state (2SS)). Arterialised blood samples were also taken at time 0 and $240 \mathrm{~min}$ for lipids. Samples were stored at $-70{ }^{\circ} \mathrm{C}$ until analysis. Continuous recordings of oxygen consumption and $\mathrm{CO}_{2}$ production were made using a ventilated canopy indirect calorimeter (Deltatrac metabolic monitor, Datex Instrumentarium, Helsinki, Finland) for two 20-min periods during 1 SS and 2SS, and four measurements for ${ }^{13} \mathrm{CO}_{2}$ enrichment were taken during the steady states to calculate palmitate oxidation. The heart rate was recorded from an electrocardiogram and blood pressure (Omron 711, Hoofddorp, Netherlands) measured at $30 \mathrm{~min}$ intervals. The test was stopped if the heart rate exceeded more than twice the resting value.

\section{Preparation of infusates}

Potassium $1-{ }^{13} \mathrm{C}$-palmitate (99\% 1-C; Mass Trace, Woburn, MA, USA) was added to $5 \mathrm{ml}$ sterile water at $60{ }^{\circ} \mathrm{C}$, passed through a millipore filter $(0.22 \mu \mathrm{m})$ into a preheated $\left(60^{\circ} \mathrm{C}\right) 50 \mathrm{ml}$ bottle of $20 \%$ human albumin solution (Bio Products Laboratory, Elstree, Herts, UK; Department of Radio-Pharmacy Royal Free Hospital) and analysed for palmitate concentration and enrichment. The exact infusion rate of the $1-{ }^{13} \mathrm{C}$-palmitate was calculated by multiplying the concentration of the isotope in the infusate by the value of the infusion rate.

Solutions of $6,6-{ }^{2} \mathrm{H}_{2}$-glucose $(99 \% \quad \mathrm{H})$ and 1,1,2,3,3- ${ }^{2} \mathrm{H}_{5}$-glycerol $(99 \% \mathrm{H})$ (Tracer Technologies, Inc., Somerville, MA, USA) were prepared in pyrogen-free $0.9 \%$ saline and passed through a Ministart $0.2 \mu \mathrm{m}$ filter (Department of Radio-Pharmacy, Royal Free Hospital).

The adrenaline infusates (adrenaline BP, Antigen Pharmaceuticals, Co. Tipperary, Ireland) were prepared as $5 \mu \mathrm{g} / \mathrm{ml}$ solutions in $0.9 \%$ saline with $1 \mathrm{mg} / \mathrm{ml}$ ascorbic acid (Medeva Pharma, Leatherhead, UK) as preservative. The exact concentration of the infusates was measured using HPLC (10). The control experiment used $0.9 \%$ saline with $1 \mathrm{mg} / \mathrm{ml}$ ascorbic acid.

\section{Derivatisation procedures}

\section{Analysis of labelled glucose, glycerol and palmitate} Plasma for $6,6-{ }^{2} \mathrm{H}_{2}$-glucose enrichment was deproteinised with ethanol and derivatised with $n$-butyl boronic acid in pyridine and acetic anhydride (11). Plasma for $1,1,2,3,3-{ }^{2} \mathrm{H}_{5}$-glycerol enrichment was deproteinised with ethanol and derivatised with acetonitrile and $N$ methyl- $N(t$-butyl-dimethylsilyl) trifluoroacetamide (12).

Plasma for $1-{ }^{13} \mathrm{C}$-palmitate enrichment was added to an internal standard of pentadecanoic acid (99\%, Sigma-Aldrich, Poole, Dorset) with extraction of carboxylate anion tetrabutylammonium cation pairs by dichloromethane and iodomethane $(13,14)$.

\section{Measurement of stable isotope enrichment and} calculations The isotopic enrichments of glucose, glycerol and palmitate were determined by separate analysis of the bis-(n-butylboronate)-monoacetylglucose, tris-( $t$-butyldimethylsilyl)glycerol and palmitate methyl ester respectively, on a Varian 3400 gas chromatograph/Finnigan Incos XL mass spectrometer (Thermoquest Ltd, Hemel Hempstead, UK). During the times 90-120 and 210-240 min, a physiological and isotopic steady state was present; therefore Steele's equation for steady state was applied to calculate the rate of appearance (Ra) or rate of disappearance (Rd) of the substrate (15).

$$
\begin{aligned}
\text { Ra substrate } & =\text { Rd substrate }(\mu \mathrm{mol} / \mathrm{min}) \\
& =\mathrm{F} / \mathrm{TTR} \text { plasma substrate }-\mathrm{F}
\end{aligned}
$$

where $\mathrm{F}$ is the infusion rate of substrate (micromoles per minute) and TTR is the tracer to tracee ratio of substrate.

Breath samples were analysed for ${ }^{13} \mathrm{C} /{ }^{12} \mathrm{C}$ ratio in a gas chromatograph isotope ratio mass spectrometer (PDZ Europa Ltd, Northwich, Cheshire, UK). Palmitate oxidation was calculated using the equations of Wolfe et al. (15):

$$
\begin{aligned}
\text { Palmitate oxidation }(\mu \mathrm{mol} / \mathrm{min})= & \mathrm{IECO}_{2} /(\mathrm{IEp} \times 0.81) \\
& \times \mathrm{VCO}_{2} \times 41.6 \times 100
\end{aligned}
$$

where $\mathrm{IECO}_{2}$ is the isotope enrichment of expired $\mathrm{CO}_{2}$ (moles percentage excess (MPE)), IEp is the isotope enrichment of palmitate (MPE) and $\mathrm{VCO}_{2}$ is the $\mathrm{CO}_{2}$ production rate $(\mathrm{ml} / \mathrm{min})$.

Palmitate concentrations were calculated from the ratio of the methylpalmitate to methylpentadecanoate (13). 
Palmitate non-oxidative metabolism was calculated by subtracting the rate of palmitate oxidation from the rate of palmitate turnover.

The metabolic clearance rate (MCR) was calculated:

MCR $(\mathrm{ml} / \mathrm{kg} \mathrm{min})=$ Ra substrate/substrate concentration $\times 1000$.

Biochemical assays Serum samples for specific insulin were analysed in duplicate by an in-house ELISA with a coefficient of variation $<8.6 \%$. This is a highly specific assay for intact insulin and the cross reactivity with proinsulin was negligible (16). Glucose was measured with a hexokinase assay (Randox, Co., Antrim, UK) on a discrete, clinical analyser (Cobas Mira, Hoffman-Laroche and Co., Basel, Switzerland). Adrenaline and noradrenaline were measured by HPLC (10). NEFA concentrations were measured by colorimetric method (Wako Chemicals, Neuss, Germany) as were glycerol, lactate and 3-hydroxybutyrate concentrations (Randox, Co. Antrim, UK). Lipids were analysed in the laboratory (Olympus AU 640 analyser, Olympus Optical Co Ltd, Eastleigh, Hants, UK).

\section{Power calculations}

Based on previous data, the study had $>86 \%$ power (at $P<0.05$, two-sided) to detect a between-group difference in lipolysis, NEFA production and oxidation, and glucose production, both basally and in response to adrenaline $(9,17)$.

\section{Statistical analysis}

Data are presented as the mean \pm s.E.M. Skewed data were log-transformed and presented as the median (interquartile range). Statistical analyses were performed in STATA 8 (Stata Corporation, College Station, TX, USA); the Mann-Whitney $U$-test and unpaired Student's $t$-test were used as appropriate. A $P<0.05$ was taken as significant. The basal data were calculated as the mean of the 1 SS data (pre- $0.9 \%$ saline and pre-adrenaline). To assess the response to the adrenaline infusion, the change in substrate concentration and turnover from 1SS to 2SS was compared in the pGDM and control groups. The change in substrate concentration and turnover from 1SS to 2 SS during the $0.9 \%$ saline infusion, representing an extended fast, was also calculated and compared between the pGDM and control groups.

\section{Results}

\section{Baseline characteristics}

The subjects were matched for FM and BMI: nine out of ten subjects in each group had a BMI between 20 and
$25 \mathrm{~kg} / \mathrm{m}^{2}, 1$ in each group had a BMI between 25 and $28 \mathrm{~kg} / \mathrm{m}^{2}$. There was no significant difference in age, waist to hip ratio or parity (Table 1).

\section{Insulin sensitivity tests and effect of insulin on NEFA metabolism}

Whole body insulin sensitivity was not significantly different in pGDM vs control women as assessed by the SITT $(29.1 \pm 3.2$ vs $30.9 \pm 1.6 \mathrm{mg} / \mathrm{l}$ per min respectively). There was no significant difference in the suppression of NEFA concentrations by insulin in pGDM vs control women $(23.9 \pm 3.7$ vs $30.2 \pm$ $2.0 \mu \mathrm{mol} / \mathrm{l}$ per $\mathrm{min}$ ).

\section{HOMA analysis}

There was no significant difference in insulin sensitivity (HOMA \%S): 41(18-79) vs 78 (21-99) \%S between the pGDM and control women respectively.

\section{Basal substrate and hormone concentrations}

Basal glucose concentrations were higher in pGDM vs control women $(96 \pm 1.7$ vs $88 \pm 1.4 \mathrm{mg} / \mathrm{dl} ; P=0.009)$. Palmitate and NEFA concentrations were lower in the pGDM group ( $81 \pm 10$ vs $178 \pm 17 \mu \mathrm{mol} / \mathrm{l} ; P=0.002$ and $610 \pm 40$ vs $780 \pm 60 \mu \mathrm{mol} / \mathrm{l} ; P=0.04$ respectively).

There was no significant difference in circulating adrenaline $(0.10 \pm 0.02$ vs $0.14 \pm 0.03 \mathrm{nmol} / \mathrm{l})$, noradrenaline $(1.36 \pm 0.1$ vs $1.05 \pm 0.07 \mathrm{nmol} / \mathrm{l})$, insulin $(63 \pm 16$ vs $72 \pm 17 \mathrm{mIU} / \mathrm{l})$, lactate $(0.49 \pm 0.04$ vs $0.43 \pm 0.03 \mathrm{mmol} / \mathrm{l})$, 3-hydroxybutyrate $(0.09 \pm 0.02$ vs $0.15 \pm 0.04 \mathrm{mmol} / \mathrm{l})$ and glycerol $(98 \pm 7$ vs $104 \pm 7 \mu \mathrm{mol} / \mathrm{l}$ ) concentrations in the pGDM vs control women respectively. There was no difference in cholesterol $(180 \pm 6$ vs $177 \pm 6 \mathrm{mg} / \mathrm{dl})$, TG $(77 \pm 4$ vs $68 \pm 7 \mathrm{mg} / \mathrm{dl}$ ) and high-density lipoprotein cholesterol $(51 \pm 2$ vs $50 \pm 4 \mathrm{mg} / \mathrm{dl})$ concentrations in pGDM vs control subjects respectively.

\section{Basal substrate appearance}

Glycerol appearance was lower in women with pGDM vs control women as expressed per kilogram body

Table 1 Comparison of anthropometric data in previous gestational diabetes (pGDM) vs control women. Data are presented as mean \pm S.E.M.

\begin{tabular}{lcc}
\hline & pGDM & Controls \\
\hline$n$ & 10 & 10 \\
Age (years) & $42 \pm 2$ & $40 \pm 2$ \\
BMl $\left(\mathrm{kg} / \mathrm{m}^{2}\right)$ & $22.8+1.0$ & $23.5 \pm 1.0$ \\
LBM $(\mathrm{kg})$ & $42.9+1.8$ & $45.9+1.7$ \\
FM $(\mathrm{kg})$ & $20.1+2.1$ & $19.2+1.5$ \\
Waist $(\mathrm{cm})$ & $77.0 \pm 2.0$ & $75.7 \pm 2.0$ \\
Waist:hip ratio & $0.81+0.01$ & $0.78 \pm 0.01$
\end{tabular}

BMI, body mass index; LBM, lean body mass; FM, fat mass. 
weight, FM and FFM (all $P<0.02$; Table 2). Palmitate appearance and oxidation were lower in women with pGDM vs controls as expressed per kilogram body weight $(P=0.03$; Table 2$)$ and FFM $(P=0.03)$. There was no significant difference in glucose appearance basally in pGDM vs control subjects (Table 2). Non-oxidative palmitate disposal was not significantly different in the pGDM vs control women: $2.67 \pm 0.34$ vs $2.93 \pm 0.17 \mu \mathrm{mol} / \mathrm{kg}$ per $\mathrm{min}$. The MCR of palmitate and glycerol was not significantly different between the pGDM and control women $(27 \pm 3$ vs $29 \pm 5 \mathrm{ml} / \mathrm{kg}$ per $\min$ and $31 \pm 3$ vs $37 \pm$ $3 \mathrm{ml} / \mathrm{kg}$ min respectively).

\section{Substrate appearance and changes during the normal saline infusion}

At the start and at the end of the $0.9 \%$ saline infusion, glucose appearance was not significantly different in the pGDM and control women (Fig. 1). With the prolonged saline infusion in the control women, glucose appearance declined in every instance (Fig. 1). In the pGDM women, it was maintained such that the change in glucose appearance was different in the two groups $(\Delta-0.33 \pm$ 0.02 vs $-0.03 \pm 0.08 \mathrm{mg} / \mathrm{kg}$ per $\mathrm{min} ; P=0.004$; Fig. 1 ). There was no significant difference between the pGDM and control subjects in glycerol appearance from 1SS to $2 \mathrm{SS}(0.30 \pm 0.04$ to $0.29 \pm 0.03 \mathrm{mg} / \mathrm{kg}$ per $\mathrm{min}$ vs $0.38 \pm 0.04$ to $0.39 \pm 0.04 \mathrm{mg} / \mathrm{kg}$ per $\mathrm{min} ; P=0.59$ respectively). The same was true for palmitate appearance $(0.88 \pm 0.18$ to $0.99 \pm 0.21 \mathrm{mg} / \mathrm{kg}$ per $\min$ vs $0.98 \pm$ 0.11 to $0.89 \pm 0.09 \mathrm{mg} / \mathrm{kg}$ per min; $P=0.33)$ and palmitate oxidation $(0.08 \pm 0.01$ to $0.09 \pm 0.01 \mathrm{mg} / \mathrm{kg}$ per min vs $0.09 \pm 0.01$ to $0.10 \pm 0.01 \mathrm{mg} / \mathrm{kg}$ per min; $P=0.74)$ in $\mathrm{pGDM}$ vs control women.

\section{Substrate and hormone concentrations and changes in response to adrenaline}

There was a significant increase in the concentrations of adrenaline, glucose, lactate, NEFA, palmitate and glycerol in response to the adrenaline infusion in both

Table 2 Basal substrate appearance in women with previous gestational diabetes (pGDM) and control women. The mean \pm S.E.M. are shown.

\begin{tabular}{cccc}
\hline & pGDM & Controls & $\boldsymbol{P}$ value \\
\hline $\begin{array}{c}\text { Glucose appearance } \\
\text { (mg/kg per min) }\end{array}$ & $1.86 \pm 0.09$ & $1.96 \pm 0.06$ & 0.32 \\
$\begin{array}{c}\text { Glycerol appearance } \\
\text { (mg/kg per min) }\end{array}$ & $0.27 \pm 0.02$ & $0.38 \pm 0.03$ & 0.02 \\
$\begin{array}{c}\text { Palmitate appearance } \\
\text { (mg/kg per min) }\end{array}$ & $0.74 \pm 0.09$ & $1.05 \pm 0.09$ & 0.03 \\
$\begin{array}{c}\text { Palmitate oxidation } \\
\text { (mg/kg per min) }\end{array}$ & $0.07 \pm 0.01$ & $0.10 \pm 0.01$ & 0.03 \\
\hline
\end{tabular}

Basal appearance of glucose, glycerol, palmitate and oxidised palmitate, derived from first steady state stable isotope study data (mean of pre- $0.9 \%$ saline and pre-adrenaline infusions), as expressed per $\mathrm{kg}$ body weight.

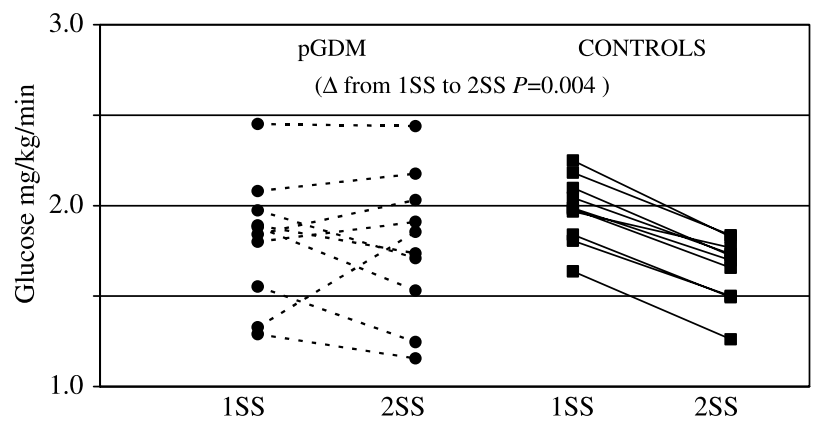

Figure 1 Glucose appearance during an extended fast (normal saline infusion) in previous gestational diabetes (pGDM) and control women. The glucose appearance rates $(\mathrm{mg} / \mathrm{kg}$ per $\mathrm{min}$ ) are shown at the first steady state (1SS) and the second steady state (2SS) in pGDM ( ) and control women ( $\boldsymbol{\square})$. The change from 1SS to 2SS was significantly greater in the control vs pGDM women.

groups (2SS vs 1SS), but the increment was similar for both (Table 3). Insulin concentrations rose more in women with pGDM vs controls $(P=0.02$; Table 3$)$. There was a significant increase in the 3-hydroxybutyrate concentrations in response to the adrenaline infusion in both groups and the rise was greater in controls vs the pGDM women $(P=0.05$; Table 3).

\section{Substrate appearance and changes in response to adrenaline}

The rate of appearance of glycerol and palmitate, and palmitate oxidation, increased in response to the adrenaline infusion (2SS vs 1SS). There was no significant difference in the change in appearance rates of glycerol, glucose, palmitate and palmitate oxidation in the pGDM vs control women (Table 4).

\section{Discussion}

Early defects in these non-obese pGDM women include elevated basal glucose concentrations, sustained glucose production during fasting, but surprisingly, reduced lipolysis, NEFA appearance and oxidation. No differences in whole body insulin action or catecholamine action were present. Therefore, abnormalities in carbohydrate and fat metabolism exist in pGDM women before the development of type 2 diabetes. These women have up to a $60 \%$ chance of developing type 2 diabetes over a 15 -year period (1).

\section{Carbohydrate metabolism}

Glucose appearance rates were similar and glucose concentrations elevated basally in the pGDM vs control women. This is in agreement with other isotope studies in NGT women with pGDM $(18,19)$, and first-degree relatives of type 2 diabetic subjects (20), a group at increased risk of diabetes. The decrease in glucose 
Table 3 Substrate and hormone concentrations in response to adrenaline. Absolute values (mean \pm S.E.M.) ${ }^{*}$ are shown. *Insulin concentrations were skewed and are shown as the median (interquartile range).

\begin{tabular}{|c|c|c|c|c|}
\hline \multirow[b]{2}{*}{ Hormone/substrate } & \multicolumn{2}{|c|}{ pGDM } & \multicolumn{2}{|c|}{ Controls } \\
\hline & $1 S S$ & 2SS & $1 S S$ & 2SS \\
\hline Adrenaline $(\mathrm{nmol} / \mathrm{l})$ & $0.10 \pm 0.02$ & $2.15 \pm 0.32$ & $0.14 \pm 0.03$ & $2.16 \pm 0.31$ \\
\hline Glucose $(\mathrm{mg} / \mathrm{dl})$ & $96 \pm 2$ & $122 \pm 7$ & $88 \pm 2$ & $109 \pm 4$ \\
\hline Lactate $(\mathrm{mmol} / \mathrm{l})$ & $0.46 \pm 0.02$ & $0.82 \pm 0.06$ & $0.44 \pm 0.04$ & $0.77 \pm 0.07$ \\
\hline NEFA $(\mu \mathrm{mol} / \mathrm{l})$ & $612+47$ & $1015+62$ & $819+63$ & $1257+74$ \\
\hline Palmitate $(\mu \mathrm{mol} / \mathrm{l})$ & $85 \pm 11$ & $142 \pm 18$ & $146 \pm 19$ & $208 \pm 19$ \\
\hline Glycerol $(\mu \mathrm{mol} / \mathrm{l})$ & $100 \pm 9$ & $131 \pm 9$ & $115 \pm 8$ & $141 \pm 3$ \\
\hline Insulin (mIU/I) & $7.15(3.26-22.39)^{*}$ & $11.40(7.06-29.69)^{\star}$ & $4.00(0.96-31.08)^{\star *}$ & $7.89(1.03-35.70)^{\star \star}$ \\
\hline 3-Hydroxybutyrate (pmol/l) & $0.08 \pm 0.04$ & $0.38 \pm 0.09$ & $0.18 \pm 0.05$ & $0.70 \pm 0.11$ \\
\hline
\end{tabular}

pGDM, previous gestational diabetes; 1SS, first steady state; 2SS, second steady state; NEFA, non-esterified fatty acid. *Insulin concentrations rose more in women with pGDM than in controls $(P=0.02) ;{ }^{\star \star}$ There was a greater increase in 3-hydroxybutyrate concentration in the control group compared with pGDM women $(P=0.05)$.

appearance from 1SS to 2SS, was greater in the control vs the pGDM subjects during the additional period of fasting involved in the $0.9 \%$ saline infusion $(P=0.004)$. The women with pGDM have an impairment in the ability to switch off glucose production, the main contributor to which is the liver, during a short fast. Although whole body insulin sensitivity was similar, as measured by the SITT and confirmed by HOMA analysis, there may be differential tissue resistance, with the liver being relatively resistant and adipose tissue relatively more sensitive to insulin. Interestingly, longitudinal studies in Pima Indians have shown that enhanced whole body insulin sensitivity predicts weight gain and insulin resistance later in life (21).

Previous studies have mainly demonstrated greater insulin resistance in pGDM women (22-26) although some have shown similar insulin sensitivities to controls (18). The variable findings may reflect the heterogeneity of the pGDM groups especially the time interval between index pregnancy and study. In this study, the pGDM women were at an early stage with each woman having experienced one GDM pregnancy controlled on diet alone. The SITT was used to assess insulin sensitivity.
Although it is a validated test that correlates well with the euglycaemic clamp (6), it may not be sufficiently discriminatory to detect subtle differences in insulin sensitivity. Although insulin secretion was not measured in our study, secretory defects are common in lean pGDM women $(2,22)$. In response to adrenaline, there was no difference in the plasma glucose or glucose appearance responses between the groups. Insulin concentrations increased more in the pGDM group suggesting again that possibly the liver is relatively resistant to insulin, although this was not assessed formally. The reason for the augmented insulin response is not clear.

\section{Fat metabolism}

Glycerol and palmitate appearance, and oxidation rates were lower basally in pGDM vs control women, as were palmitate and NEFA concentrations. These differences were not attributable to differences in clearance rates. The relative decrease in the availability of fat as an energy substrate basally and the lower NEFA oxidation implies a tendency to store fat although the palmitate non-oxidative disposal, representing mainly

Table 4 Substrate rate of appearance in response to adrenaline. Absolute values (mean \pm S.E.M.) are shown.

\begin{tabular}{|c|c|c|c|c|}
\hline \multirow[b]{2}{*}{ Substrate appearance } & \multicolumn{2}{|c|}{ pGDM } & \multicolumn{2}{|c|}{ Controls } \\
\hline & $1 S S$ & 2SS & 1SS & 2SS \\
\hline \multicolumn{5}{|l|}{ Glycerol appearance } \\
\hline$(\mathrm{mg} / \mathrm{kg}$ per $\mathrm{min})$ & $0.24 \pm 0.02$ & $0.46 \pm 0.04$ & $0.39 \pm 0.04$ & $0.75 \pm 0.09$ \\
\hline$(\mu \mathrm{mol} / \mathrm{kg}$ per $\mathrm{min})$ & $2.63 \pm 0.21$ & $5.00 \pm 0.43$ & $4.24 \pm 0.43$ & $8.15 \pm 0.98$ \\
\hline \multicolumn{5}{|l|}{ Glucose appearance } \\
\hline (mg/kg per min) & $1.89 \pm 0.11$ & $2.09 \pm 0.11$ & $1.94 \pm 0.10$ & $2.09 \pm 0.19$ \\
\hline ( $\mu \mathrm{mol} / \mathrm{kg}$ per min) & $10.50 \pm 0.61$ & $11.61+0.61$ & $10.77 \pm 0.55$ & $11.61 \pm 1.00$ \\
\hline \multicolumn{5}{|l|}{ Palmitate appearance } \\
\hline (mg/kg per min) & $0.62 \pm 0.08$ & $1.18 \pm 0.18$ & $1.04 \pm 0.11$ & $1.43 \pm 0.12$ \\
\hline ( $\mu \mathrm{mol} / \mathrm{kg}$ per $\min )$ & $2.42 \pm 0.31$ & $4.61 \pm 0.70$ & $4.06 \pm 0.43$ & $5.58 \pm 0.47$ \\
\hline \multicolumn{5}{|l|}{ Palmitate oxidation } \\
\hline (mg/kg per min) & $0.06 \pm 0.01$ & $0.12 \pm 0.02$ & $0.14 \pm 0.04$ & $0.19 \pm 0.04$ \\
\hline$(\mu \mathrm{mol} / \mathrm{kg}$ per min) & $0.24 \pm 0.04$ & $0.46 \pm 0.08$ & $0.56 \pm 0.16$ & $0.76 \pm 0.16$ \\
\hline
\end{tabular}

Substrate appearance increased in both groups in response to adrenaline. The change from 1SS to 2SS was not different between the two groups. pGDM, previous gestational diabetes; $1 \mathrm{SS}$, first steady state; 2SS, second steady state. 
re-esterification, was not significantly different between the groups. These subjects were non-obese and matched carefully for FM and therefore the metabolic differences described are likely to be of primary importance in the pathogenesis of type 2 diabetes. It is difficult to ascertain the impact of diabetes itself on lipolysis and NEFA kinetics, separate from obesity: the two conditions frequently co-exist and obesity itself is associated with lower lipolysis, NEFA appearance and oxidation (9). Most studies have failed to match for body composition, but in those where obese type 2 diabetic men have been matched for body weight and FM with controls, NEFA uptake and oxidation were diminished (27). The pGDM subjects had non-significantly greater fasting insulin concentrations and it may be that this contributed to the lower lipolytic and fatty acid oxidation rates. Although suppression of NEFA metabolism was not significantly different during the SITT, it may be with a more physiological dose of insulin. This requires further investigation.

Weight reduction in obese type 2 diabetic subjects fails to improve NEFA oxidation (28). This suggests that it may be a primary defect, in keeping with the findings of this study. However, when studying the diabetic state, the defects may be adaptive or secondary responses rather than primary. In men with impaired glucose tolerance (27) (at risk of type 2 diabetes) and nutritionally stunted children (29) (at increased risk of obesity), diminished NEFA oxidation is seen, again suggesting that it may be a primary defect in both type 2 diabetes and obesity. It could reflect mitochondrial dysfunction, as observed in insulin-resistant offspring of subjects with type 2 diabetes (30). Susceptibility genes for mitochondrial dysfunction have been described previously $(31,32)$. Possible mechanisms for the lower lipolysis and NEFA appearance in the pGDM group include; adipose tissue receptor differences e.g. fewer $\beta$-adrenoceptors or increased $\alpha 2$ receptors (33) or insulin receptors. In protein-restricted rats, at high risk of developing diabetes (34), adipocytes are smaller and have increased numbers of insulin receptors (35) leading to locally increased insulin sensitivity (34). This is observed despite decreased insulin sensitivity in the muscle. Post-receptor mechanisms may be involved (36). An imbalance between NEFA uptake and oxidation could promote accumulation of lipids within skeletal muscle leading to skeletal muscle insulin resistance (27). The lower rate of basal glycerol and palmitate appearance in the presence of higher plasma glucose concentrations suggests greater insulin action in adipose tissue relative to the liver. The lower NEFA turnover coupled with the elevated glucose concentrations is not compatible with increased NEFA turnover driving glucose production (37). The pGDM women may have a subnormal ability to oxidise NEFA, secondary to raised glucose concentrations, which may increase malonyl coenzyme A concentrations and thus inhibit mitochondrial NEFA transport (38). Adrenaline has not been given to women with pGDM before. The increase in 3-hydroxybutyrate production in response to the adrenaline infusion was smaller in women with pGDM vs controls, and this may indicate a subtle defect in NEFA metabolism; no other differences were seen. In contrast, people with established type 2 diabetes have predominantly shown diminished lipolysis (39), NEFA appearance and oxidation in response to catecholamines. Similar results are observed in obesity (9). In conclusion, in a group of non-obese, NGT women at increased risk of diabetes, we found sustained glucose production during fasting and reduced lipolysis, NEFA appearance and oxidation, which may promote fat storage. These observations could be primary defects in the pathogenesis of type 2 diabetes and are not readily attributable to differences in insulin or catecholamine sensitivity.

\section{Acknowledgements}

S Forbes was supported by a Novo Nordisk UK fellowship, charity number 1056410. We thank Bruce Patterson for invaluable advice on palmitate appearance assessment.

\section{References}

1 O' Sullivan JB. Diabetes mellitus after GDM. Diabetes 199140 (Suppl 2) 131-135.

2 Catalano PM, Bernstein IM, Wolfe RR, Srikanta S, Tyzbir E \& Sims EA. Subclinical abnormalities of glucose metabolism in subjects with previous gestational diabetes. American Journal of Obstetrics and Gynecology $19861551255-1262$.

3 Chan SP, Gelding SV, McManus RJ, Nicholls JS, Anyaoku V, Niththyananthan R, Johnston DG \& Dornhorst A. Abnormalities of intermediary metabolism following a gestational diabetic pregnancy. Clinical Endocrinology 199236 417-420.

4 Kousta E, Lawrence NJ, Godsland IF, Penny A, Anyaoku V, Millauer BA, Cela E, Johnston DG, Robinson S \& McCarthy MI. Insulin resistance and beta-cell dysfunction in normoglycaemic European women with a history of gestational diabetes. Clinical Endocrinology 200359 289-297.

5 WHO. Definition, Diagnosis and Classification of Diabetes Mellitus and its Complications, Report of a WHO consultation, 1999.

6 Gelding SV, Robinson S, Lowe S, Niththyananthan R \& Johnston DG. Validation of the low dose short insulin tolerance test for evaluation of insulin sensitivity. Clinical Endocrinology $199440611-615$.

7 Matthews DR, Hosker JP, Rudenski AS, Naylor BA, Treacher DF \& Turner C. Homeostasis model assessment: insulin resistance and beta-cell function from fasting plasma glucose and insulin concentrations in man. Diabetologia 198528 412-419.

8 Levy JC, Matthews DR \& Hermans MP. Correct homeostasis model assessment (HOMA) evaluation uses the computer program. Diabetes Care 199821 2191-2192.

9 Webber J, Taylor J, Greathead H, Dawson J, Buttery PJ \& Macdonald IA. A comparison of the thermogenic, metabolic and haemodynamic responses to infused adrenaline in lean and obese subjects. International Journal of Obesity and Related Metabolic Disorders 199418 717-724.

10 Forster CD \& Macdonald IA. The assay of the catecholamine content of small volumes of human plasma. Biomedical Chromatography 199913 209-215. 
11 Weicko JA \& Sherman WR. Boroacetylation of carbohydrates. Correlation between structure and mass spectral behaviour in monoacetyl hexose cyclic boronic esters. Journal of the American Chemical Society 197698 7631-7637.

12 Magni F, Arnoldi L, Monti L, Piatti P, Pozzza G \& Galli Kienle M. Determination of plasma glycerol isotopic enrichment by gas chromatography-mass spectrometry: an alternative glycerol derivative. Analytical Biochemistry $1993211327-328$.

13 Patterson BW, Zhao G, Elias N, Hachey DL \& Klein S. Validation of a new procedure to determine plasma fatty acid concentration and isotopic enrichment. Journal of Lipid Research $1999 \mathbf{4 0}$ 2118-2124.

14 Patterson BW, Zhao G \& Klein S. Improved accuracy and precision of gas chromatography/mass spectrometry measurements for metabolic tracers. Metabolism 199847 706-712.

15 Wolfe RR. Radioactive and Stable Isotope Tracers in BiomedicinePrinciples and Practice of Kinetic Analysis. New York: Wiley-Liss, 1988.

16 Anyaoku VA \& Johnston DG. Rapid specific and sensitive enzyme linked immunosorbent assay for intact insulin. Diabetalogia 1995 38 (Suppl A) 157.

17 Connacher AA, Bennet WM, Jung RT, Bier DM, Smith CC, Scrimgeour CM \& Rennie MJ. Effect of adrenaline infusion on fatty acid and glucose turnover in lean and obese human subjects in the post-absorptive and fed states. Clinical Science 199181 635-644.

18 Dornhorst A, Edwards SG, Nicholls JS, Anyaoku V, McLaren D, Heslop KE, Elkeles RS, Beard RW \& Johnston DG. A defect in insulin release in women at risk of future non-insulin-dependent diabetes. Clinical Science 199181 195-199.

19 Buchanan TA, Xiang AH, Kjos SL, Trigo E, Lee WP \& Peters RK. Antepartum predictors of the development of type 2 diabetes in Latino women 11-26 months after pregnancies complicated by gestational diabetes. Diabetes 199948 2430-2436.

20 Nielsen MF, Nyholm B, Caumo A, Chandramouli V, Schumann WC, Cobelli C, Landau BR, Rizza RA \& Schmitz O. Prandial glucose effectiveness and fasting gluconeogenesis in insulin-resistant firstdegree relatives of patients with type 2 diabetes. Diabetes 200049 2135-2141.

21 Swinburn BA, Nyomba BL, Saad MF, Zurlo F, Raz I, Knowler WC, Lillioja S, Bogardus C \& Ravussin E. Insulin resistance associated with lower rates of weight gain in Pima Indians. Journal of Clinical Investigation 199188 168-173.

22 Ryan EA, Imes S, Liu D, McManus R, Finegood DT, Polonsky KS \& Sturis J. Defects in insulin secretion and action in women with a history of gestational diabetes. Diabetes 199544 506-512.

23 Ward WK, Johnston CL, Beard JC, Benedetti TJ \& Porte D Jr. Abnormalities of islet B-cell function, insulin action, and fat distribution in women with histories of gestational diabetes: relationship to obesity. Journal of Clinical Endocrinology and Metabolism 198561 1039-1045.

24 Efendic S, Hanson U, Persson B, Wajngot A \& Luft R. Glucose tolerance, insulin release, and insulin sensitivity in normal-weight women with previous gestational diabetes mellitus. Diabetes 1987 36 413-419.

25 Kautzky Willer A, Prager R, Waldhausl W, Pacini G, Thomaseth K, Wagner OF, Ulm M, Streli C \& Ludvik B. Pronounced insulin resistance and inadequate beta-cell secretion characterize lean gestational diabetes during and after pregnancy. Diabetes Care 199720 1717-1723.

26 Robinson S, Niththyananthan R, Anyaoku V, Elkeles RS, Beard RW \& Johnston DG. Reduced postprandial energy expenditure in women predisposed to type 2 diabetes. Diabetic Medicine 199411 545-550.

27 Mensink M, Blaak EE, van Baak MA, Wagenmakers AJ \& Saris WH. Plasma free fatty acid uptake and oxidation are already diminished in subjects at high risk for developing type 2 diabetes. Diabetes 200150 2548-2554.

28 Blaak EE, Wolffenbuttel BH, Saris WH, Pelsers MM \& Wagenmakers AJ. Weight reduction and the impaired plasma-derived free fatty acid oxidation in type 2 diabetic subjects. Journal of Clinical Endocrinology and Metabolism 200186 1638-1644.

29 Hoffman DJ, Sawaya AL, Verreschi I, Tucker KL \& Roberts SB. Why are nutritionally stunted children at increased risk of obesity? Studies of metabolic rate and fat oxidation in shantytown children from Sao Paulo, Brazil. American Journal of Clinical Nutrition 2000 $72702-707$.

30 Petersen KF, Dufour S, Befroy D, Garcia R \& Shulman GI. Impaired mitochondrial activity in the insulin-resistant offspring of patients with type 2 diabetes. New England Journal of Medicine 2004350 664-671.

31 Ling C, Poulsen P, Carlsson E, Ridderstrale M, Almgren P, Wojtaszewski J, Beck-Nielsen H, Groop L \& Vaag A. Multiple environmental and genetic factors influence skeletal muscle PGC1alpha and PGC-1beta gene expression in twins. Journal of Clinical Investigation 2004114 1518-1526.

32 Shuldiner AR \& McLenithan JC. Genes and pathophysiology of type 2 diabetes: more than just the Randle cycle all over again. Journal of Clinical Investigation 2004114 1414-1417.

33 Jensen MD. Lipolysis: contribution form regional fat. Аnnual Review of Nutrition 199717 127-139.

34 Ozanne SE. Programming of hepatic and peripheral tissue insulin sensitivity by maternal protein restriction. Biochemical Society Transactions 199927 94-97.

35 Shepherd PR, Crowther NJ, Desai M, Hales CN \& Ozanne SE. Altered adipocyte properties in the offspring of protein malnourished rats. British Journal of Nutrition $1997 \mathbf{7 8} 121-129$.

36 Blaak EE. Adrenergically stimulated fat utilization and ageing. Annals of Medicine 200032 380-382.

37 Randle P, Garland PB, Hales CN \& Newsholme EA. The glucose fatty acid cycle. Its role in insulin sensitivity and the metabolic disturbances of diabetes mellitus. Lancet 19631 785-789.

38 Kelley DE, Goodpaster B, Wing RR \& Simoneau JA. Skeletal muscle fatty acid metabolism in association with insulin resistance, obesity, and weight loss. American Journal of Physiology 1999277 E1130-E1141.

39 Puhakainen I, Koivisto VA \& Yki Jarvinen H. Lipolysis and gluconeogenesis from glycerol are increased in subjects with noninsulin-dependent diabetes mellitus. Journal of Clinical Endocrinology and Metabolism 199275 789-794.

Received 31 January 2006

Accepted 3 July 2006 